\title{
Amplification of genome-integrated BeYDV replicons by transient expression of Rep in Arabidopsis thaliana
}

\author{
Yong-Sun Moon \\ College of Natural Resources \\ Department of Horticulture \\ Yeungnam University \\ 214-1 Dae-dong, Gyeongsan-si \\ Gyeongsangbuk-do, 712-749 \\ Republic of Korea \\ Kathleen L. Hefferon* \\ Cornell Research Foundation \\ Cornell University \\ 20 Thornwood Dr., Ithaca \\ NY 14850 USA \\ Tel: 6072571081 \\ Fax: 6072541015 \\ E-mail:klh22@cornell.edu
}

Financial support: This work comprises a portion of Dr. Moon's doctoral thesis at Cornell University, and was partially supported by DARPA grant N65236-98-1-5411, the Department of Horticulture and an Albert S. Roe fellowship at Cornell University.

Keywords: Agrobacterium-mediated expression, BeYDV-based vector, gene amplification, GUS expression, Rep expression, transgenic Arabidopsis.

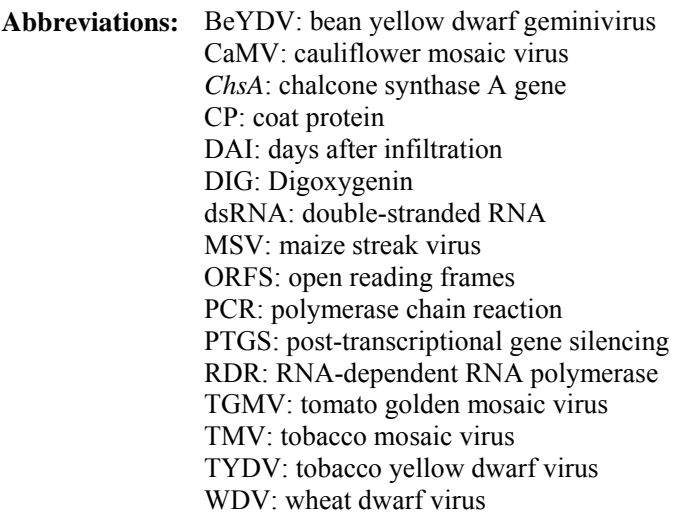

Bean yellow dwarf geminivirus (BeYDV) has been used as a potential vector to improve foreign gene expression, specifically, to achieve higher yields of vaccine proteins in plants. Previously, we have shown that when the BeYDV replication initiator protein Rep was provided in trans, replication and gene expression of GUS were enhanced enormously from a BeYDV expression vector in a transient assay system. In this paper, transgenic lines of Arabidopsis (cv. Columbia) were generated harboring the BeYDV cis-acting elements required for replication. Constructs encoding BeYDV Rep or intronless Rep open reading frames (ORFs) were transiently introduced into transgenic plants via Agrobacterium-mediated infiltration in order to examine the relative levels of replication and expression of the genome-integrated GUS reporter gene. This study shows that expression of Rep protein was regulated in trans from a separate cassette which enabled the rescue, replication and enhancement of the genome-integrated GUS gene in transgenic Arabidopsis. We conclude that Rep expression can be effectively controlled in Arabidopsis plants, and that regulation of Rep expression can result in the amplification of a genomeintegrated foreign gene by circumventing the negative effects of gene silencing.

The production of heterologous proteins in plants at quantities sufficient for practical use remains a constant challenge for scientists. For example, the development of transgenic plants which express vaccine proteins against a number of infectious diseases has increasingly become of great interest (Walmsley and Arntzen, 2000; Hefferon, 2007; Streatfield and Howard, 2003; Ma et al. 2005;

*Corresponding author 


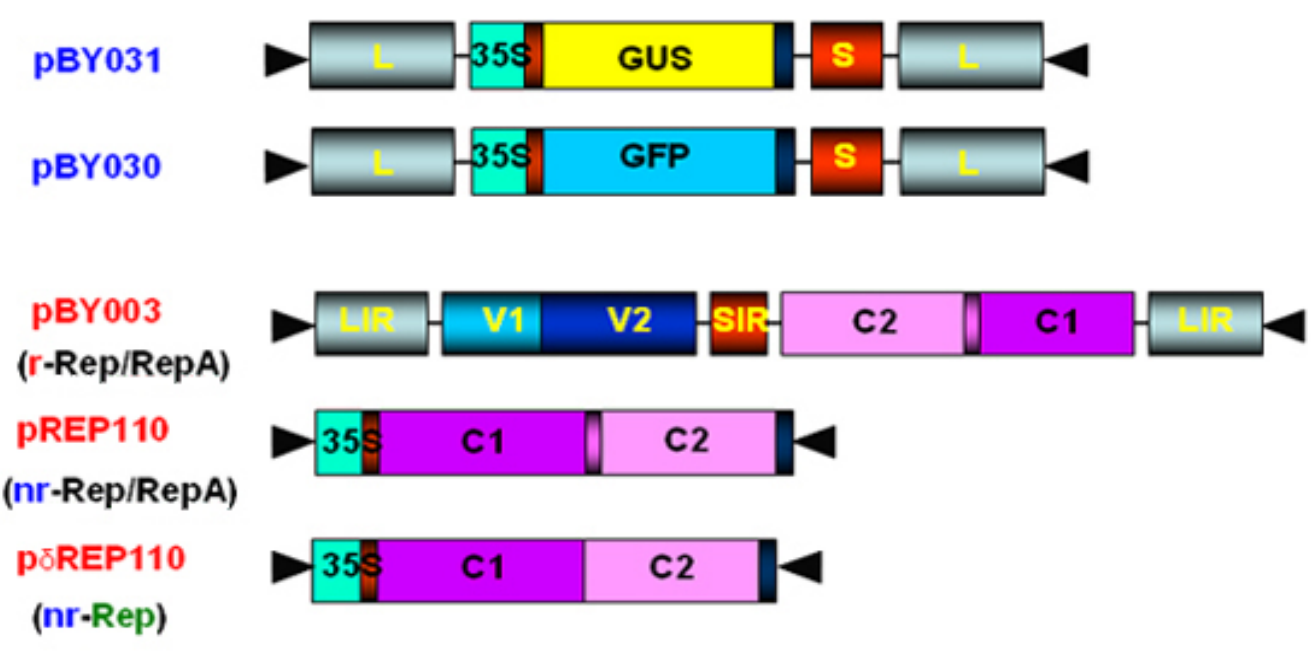

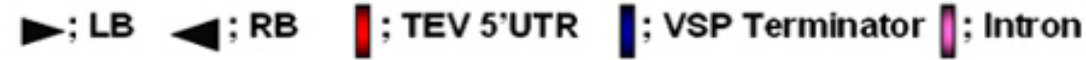

Figure 1. Schematic views of vector constructs. Each color represents different elements. The black arrows show left border (LB) and right border (RB) in the binary vector. pBY031 GUS driven by 35S promoter was replaced with GFP and designated pBY030. Three different forms of Rep gene were cloned in the binary vector and designated pBY003 (entire virus genome), pREP110 (unspliced version of Rep under 35S promoter control), and pठREP110 (spliced version of Rep under 35S promoter control). Three constructs were used for Agrobacterium-mediated infiltration of Arabidopsis plants.

Hefferon, 2006). However, a number of stumbling blocks have been identified. One of the greatest hurdles has been the development of vaccine proteins in plants at quantities sufficiently high enough to induce a mucosal immune response. To circumvent this and other problems, a number of plant viruses have been developed as potential expression vectors. Among these are: tobacco mosaic virus (TMV), potato virus X (PVX), cauliflower mosaic virus (CaMV), tobacco rattle virus (TRV), and tomato golden mosaic virus (TGMV) (Kumagai et al. 1995; Kjemtrup et al. 1998; Ruiz et al. 1998; Ratcliff et al. 2001; Hefferon, 2006).

Plant virus-based vectors have been used both for overexpression and suppression of genes in plants. (Lindbo et al. 2001) Of these, geminiviruses are considered to be excellent candidates as vectors for foreign gene expression due to the ease at which their small single-stranded DNA genome can be manipulated as well as their ability to produce high copy numbers of replicons (episomes) in the nuclei of plant cells. Furthermore, geminiviruses utilize the host replication machinery and require only one viral protein, the Rep protein, for DNA replication, thus simplifying the application of geminiviruses for expression vector technologies enormously (Hanley-Bowdoin et al. 1990; Timmermans et al. 1992; Moon and Hefferon, 2006).

Geminiviruses have also successfully been used as vectors for silencing endogenous plant genes as well as evoking a virus-induced gene silencing mechanism by the plant host during virus infection. Evidence that geminiviruses are capable of triggering this defence mechanism arises from the fact that both endogenous genes and transgenes could be silenced when TGMV, a bipartite begomovirus, was used as a silencing vector (Kjemtrup et al. 1998). Silencing systems have also been developed using the monopartite mastrevirus tobacco yellow dwarf virus (TYDV) as the vector system and petunia as the host plant. When the chalcone synthase A gene (ChsA) was cloned into a TYDVbased vector driven by the $35 \mathrm{~S}$ CaMV promoter, random white-spotted flowers were observed. This phenotype was thought to be due to an enhancement of episome copy number which in turn provoked the silencing pathway (Atkinson et al. 1998).

Mastreviridae constitute a family of geminiviruses and include such members as the type member maize streak virus (MSV), and wheat dwarf virus (WDV), both of which possess monopartite genomes, infect monocotyledonous plants and are transmitted by leafhoppers. Exceptions to the rule are TYDV and bean yellow dwarf virus (BeYDV), which infect dicotyledonous plants but retain all other attributes of the mastreviridae. BeYDV, a mastrevirus isolated from South Africa, possesses three overlapping open reading frames (ORFs) encoding four different genes which are oriented bidirectionally around long and short intergenic regions known as LIR and SIR, respectively. The replication initiator protein, or Rep protein, is encoded by overlapping ORFs $\mathrm{C} 1$ and $\mathrm{C} 2$ and is expressed from the complementary-sense strand of the BeYDV genome. An 86 nt intron spans the overlapping region and is spliced out during Rep expression. The $\mathrm{C} 1$ open reading frame encodes 
RepA, which is expressed from the unspliced transcript. The virion-sense strand contains ORFs V1 and V2, which encode the movement protein (MP) and coat protein (CP), respectively (Morris et al. 1992; Liu et al. 1998; Moon and Hefferon, 2006).

Mastrevirus replication is thought to follow a rolling-circle model. First, a complementary-sense DNA strand is synthesized from a primer located within the SIR to form a double-stranded DNA intermediate. Rep then binds to a hairpin structure, located within the LIR, and creates a nick in the virion-sense strand. Multiple copies of the virionsense strand are generated by DNA synthesis and strand displacement, all orchestrated by Rep. The newly synthesized DNA strand is then religated to form a circular, single-stranded molecule (Donson et al. 1984; Hayes et al. 1988; Kammann et al. 1991; Liu et al. 1998; Moon and Hefferon, 2006).

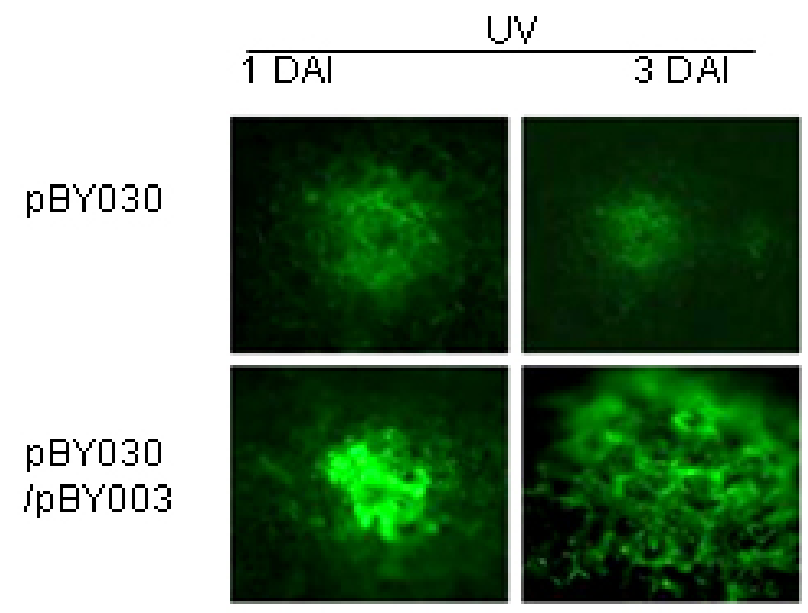

Figure 2. Enhanced GFP expression by Rep provision in trans using Agrobacterium-mediated infiltration. Wild type Arabidopsis (cv. Columbia) leaf samples were observed at 1 and 3 DAI for GFP fluorescence under UV light in microscope. Leaf samples were also observed under white light (18 milliseconds white light) as a control (data not shown). Exposure to UV light was one sec for $1 \mathrm{DAl}, 2.3 \mathrm{sec}$ for 3 DAl leaf samples.

Recently, alternative approaches have been used to render plant viral expression vectors less host-specific and to improve safety by removing the possible production of infectious virus particles which could escape from the host plant. In this new approach, virus amplification can take place by agrodelivery or by integration into the host genome, followed by controlled release from a chromosomal location. This results in the release of replicons throughout the host from a chromosomally encoded pro-replicon or pro-virus, thus eliminating the requirement for cell-to-cell spread of the expression vector (Hefferon, 2006). This 'deconstructed virus strategy' has been examined in a novel TMV-based vector system in which various models of the viral vector were differentially transformed into Agrobacteria and delivered into plants, where the modules could be reassembled and the gene of interest expressed at extremely high yields (Gleba et al. 2004; Gleba et al. 2005; Marillonnet et al. 2005).

Development of a similar system by means of a geminivirus as the expression vector has also been underway. Using transient assays, Timmermans et al. (1992) reported the ability of Rep of WDV to initiate replication in trans. Similarly, when supplied from a separate expression cassette under independent promoter control and distinct from the rest of the virus expression vector elements required for replication, Rep of BeYDV was shown to enhance replication and gene expression in a transient assay system (Hefferon and Dugdale, 2003; Mor et al. 2003). In this paper, we generated transgenic Arabidopsis thaliana plants which contain an integrated expression cassette consisting of two copies of the LIR and one copy of the SIR (known as LSL) of BeYDV. We demonstrate that regulated Rep protein can release a genome-integrated GUS gene to form a replicating cassette, which then replicates extrachromosomally and increases gene expression greatly. We also show the capability of this expression system to function efficiently without succumbing to the consequences of gene silencing in the host plant. We examine the parameters to which this expression system can be utilized to its greatest potential. The implications of these results with respect to future virus expression vector technologies are discussed.

\section{MATERIALS AND METHODS}

\section{Vector constructs}

pBY028 was cloned into the pGPTV-Kan binary vector and designated pBY031 as described in detail in Mor et al. (2003). The backbone vector of pBY002 was replaced with the binary vector pBIN19-Kan (Becker et al. 1992; Liu et al. 1998) and designated pBY003 for Agrobacteriummediated DNA delivery. The LSL cassette with GFP was inserted into the pGPTV-Kan binary vector and designated pBY030 (Mor et al. 2003). Binary vectors were transformed into Agrobacterium tumefaciens LBA4404, and the resulting lines were confirmed by polymerase chain reaction (PCR) and restriction digestion. In addition, different forms of Rep were cloned into the binary vector pGPTV-Kan and were designated pREP110 (pBY036; the unspliced Rep) or pəREP110 (pBY037; the spliced, intronless form of Rep) respectively (Figure 1).

\section{Agrobacterium-mediated stable transformation}

The floral dip transformation method of Clough and Bent (1998) was utilized for production of Arabidopsis transgenic lines. Immature flower buds of wild type Arabidopsis cv. Columbia were dipped into pBY031 


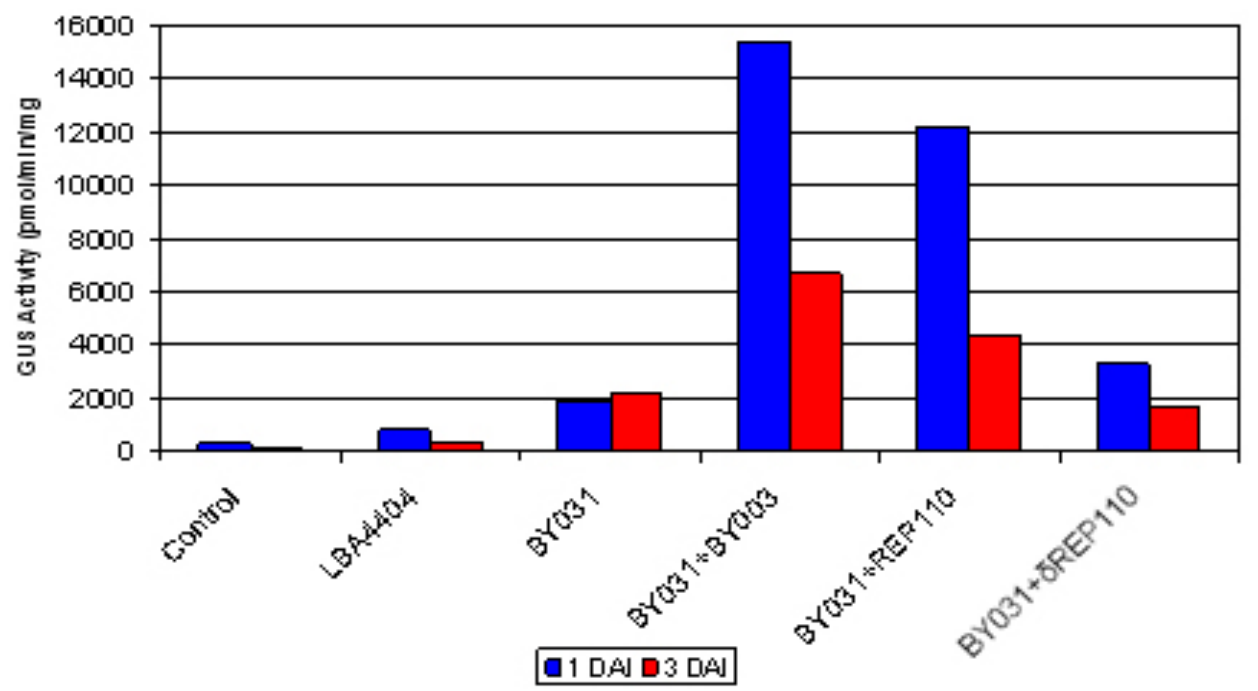

Figure 3. Transient expression of LSL-GUS gene in wild type Arabidopsis (cv. Columbia) either with or without Rep expression. Control is water treated leaf samples while Agrobacterium strain LBA4404 is used as a negative control. pBY031 was mixed with Agrobacterium harboring pBY003, pREP110, or p2REP110. Leaf samples were harvested 1 and 3 DAI, and GUS enzymatic assay was performed.

Agrobacterium solution for $30 \mathrm{sec}$ with little agitation for transformation. When seeds were harvested, they were sterilized and grown on kanamycin selective plates $(1 / 2$ strength MS salt, MSV1 vitamins, $0.01 \%$ myo-inositol, $3 \%$ sucrose, $0.8 \%$ Bacto agar, and $50 \mathrm{mg} / 1$ kanamycin) for selection. Seedlings which were resistant to kanamycin were transplanted to soil for further growth.

For Bar gene selection, seeds were sowed directly to MetroMixTM soil. BASTATM, (bialaphos) was sprayed (60 $\mathrm{mg} / \mathrm{l}$ final concentration), and resistant seedlings were transplanted into bigger pots. PCR confirmation was performed with Rep (814 bp) gene specific primers (REPrev; 5'-TTT TCC ATA TTT AGG GTT GAC AGT-3' and REPfor; 5'-TCA CAC CTT TTC TTA TTT TCT TCC3'), and RepA (540 bp) primers (RepAfor; 5'-AAC TCA CAC CTT TTC TTA TTT TCT-3' and RepArev; 5'-ATT GTG CTT GAT CGT AGG AG-3'). In addition, the uidA (GUS) gene specific primers were used (462 bp) (GUSlower; 5'-GTC CCG CTA GTG CCT TGT CCA GTT-3' and GUSupper; 5'-GGG CAG GCC AGC GTA TCG TG-3'.

\section{Agrobacterium-mediated leaf infiltration for transient Rep expression}

The Agrobacterium-mediated infiltration method of Tang et al. (1996) was modified for Arabidopsis. Each Agrobacterium (LBA4404) containing pBY031, pBY003, pREP110, or pəREP110 was incubated in $2 \mathrm{ml}$ of YENB $(0.75 \%$ yeast extract, $0.8 \%$ nutrient broth $)$ media with kanamycin $(50 \mathrm{mg} / \mathrm{ml})$ for $18 \mathrm{hrs}$ at $30^{\circ} \mathrm{C}$, transferred to 10 $\mathrm{ml}$ of YENB-Kan, and incubated for $24 \mathrm{hrs}$ at $30^{\circ} \mathrm{C}$. The cells were harvested by centrifugation $(7,000 \mathrm{rpm}$ for 10 $\min$ at $4^{\circ} \mathrm{C}$ ) and washed with an equal volume of $10 \mathrm{mM}$ MES (pH 5.5) buffer. Cells were suspended in $10 \mathrm{mM}$ MES buffer with $200 \mu \mathrm{M}$ acetosyringone as an inducer to get OD $=0.5$ at $600 \mathrm{~nm}$ and incubated for one $\mathrm{hr}$ at room temperature. One $\mathrm{ml}$ of Agrobacterium suspension was infiltrated into leaves of wild type Arabidopsis thaliana (cv. Columbia). Each pot contained four plants. Water or LBA4404 were injected into wild type plants as a negative control for transient GUS and Rep assay. For each independent experiment, the five different GUS transgenic Arabidopsis thaliana (cv. Columbia) lines were grown in the light room (16 hrs light / 8 hrs dark photoperiod, $\left.23^{\circ} \mathrm{C}\right)$. Six to eight week-old transgenic leaves were infiltrated with Agrobacterium pBY003 suspension for GUS histochemical staining using the same method described previously. In addition, Agrobacterium strains harboring pREP110, p $\delta$ REP110, or pBY003 were infiltrated into GUS transgenic leaves. Leaf samples were harvested 1 and 3 days after infiltration (DAI). Right before the experiment, leaves were collected at day 0 as control. Ground leaf samples were divided into three parts (one part for GUS assay, sec part for RNA blot analysis, and the rest for DNA blot analysis).

\section{GUS histochemical staining and enzymatic assay}

The procedures of Rodrigues-Pousada et al. (1993) and Jefferson et al. (1987) were modified for GUS histochemical staining (Jefferson et al. 1987; RodriguesPousada et al. 1993). Ice-cold $90 \%$ acetone was added to the leaves. After $20 \mathrm{~min}$ incubation on ice, leaf samples were rinsed with $50 \mathrm{mM}$ sodium phosphate buffer ( $\mathrm{pH}$ 7.2) for $20 \mathrm{~min}$ at room temperature $\left(25^{\circ} \mathrm{C}\right)$. Two $\mathrm{ml}$ of GUS staining solution was added $(100 \mathrm{mM}$ sodium phosphate 
buffer (pH 7.2), $10 \mathrm{mM}$ EDTA, $1 \mathrm{mM}$ Triton X-100, and 1 $\mathrm{mM}$ X-Gluc (cyclohexyl ammonium salt in N.N-dimethyl formamide)). Samples were subjected to a vacuum for 10 $\min$ in a desiccator, and then incubated for $16 \mathrm{hrs}$ at $37^{\circ} \mathrm{C}$. After staining, the leaves were rinsed for one min each with a series of ethanol $(15 \%, 30 \%, 50 \%, 70 \%, 85 \%, 95 \%$, and $100 \%$ ). Published procedures (Jefferson et al. 1987; Allen et al. 1993) were used for the GUS enzymatic assay. Fine powder of leaf samples were ground by a FastPrepTM machine for $30 \mathrm{sec}$ at speed 5 with three volumes of GUS extraction buffer (50 nM NaPO4, pH 7.0, 0.1\% SDS, 10 $\mathrm{mM}$ Na2EDTA and $10 \mathrm{mM}$ 2-mercaptoethanol), and total protein concentrations were determined by Bradford assay (BioRad) using BSA as a standard (Bradford, 1976). GUS activities were determined by fluormetric assay using $1 \mathrm{mM}$ 4-methylumbelliferyl B-D-glucuronide (MUG) as substrate and 4-methylumbelliferone (MU) as standard, and results were monitored by fluormetry (DYNEX technologies Fluorolite 1000). Data have been presented here in $\mu \mathrm{mol} / \mathrm{min} / \mathrm{mg}$ total protein.

\section{Northern blot analysis and Southern blot analysis}

For leaf RNA extraction, one ml of TRIzol (Invitrogen) was added to $100 \mathrm{mg}$ of leaf sample using one ceramic bead, and samples were destroyed by a FastPrepTM machine for $30 \mathrm{sec}$ at speed 5. After a brief incubation, $200 \mu \mathrm{l}$ of chloroform was added and the aqueous phase was extracted. $500 \mu \mathrm{l}$ of iso-propanol was added to the aqueous phase. Precipitated RNA was washed with $70 \%$ ethanol and dissolved into DEPC-treated water. Total RNA concentrations were measured by spectrophotometer. One $\%$ agarose gel was prepared with $1 \mathrm{X}$ MOPS buffer. Five $\mu \mathrm{g}$ of total RNA was dried under the Speed-VacTM vacuum drier for $15 \mathrm{~min}$. The pelleted RNA was suspended in $5.5 \mu \mathrm{l}$ of DEPC-treated water, and $14.5 \mu 1$ of RNA denaturing solution was added (0.5X MOPS buffer, $17.5 \%$ formaldehyde, and $50 \%$ formamide). Total RNA was denatured at $65^{\circ} \mathrm{C}$ for $15 \mathrm{~min}$ and quenched on ice. After pre-running the gel for $5 \mathrm{~min}$ at 100 volts, samples were loaded immediately. The gel was run with $1 \mathrm{X}$ MOPS buffer for two hrs at 80 volts, then blotted onto a Zeta-probeTM nylon membrane for three hrs with $25 \mathrm{mM}$ sodium phosphate buffer ( $\mathrm{pH}$ 6.5) using the downward capillary transfer method. After transferring, both sides of the membrane were irradiated using a UV auto cross linker. (Sambrook et al. 1989) The membrane was stained with methylene blue and destained with water. After two hrs of pre-hybridization at $50^{\circ} \mathrm{C}$, the membrane was hybridized with Digoxygenin (DIG)-labeled probes that had been prepared previously (Mor et al. 2003). DIG-labeled probes were synthesized using the DIG-PCR probe synthesis kit (Boehringer-Mannheim) with the primers GUS1012 (5'CTTACGCTGAAGAGATGCTCGAC) and GUSrev (5'TTTGCGGTCGCGAGTGAAGATCC) for the uidA genespecific probe $(\sim 0.7 \mathrm{~kb})$ and the primers NcoREP and
SacREP for the rep gene-specific probe $(\sim 1 \mathrm{~kb})$. Hybridization and detection were done according to manufacturer's protocol (Roche).

\section{Line 1}

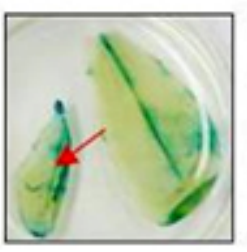

Line 2

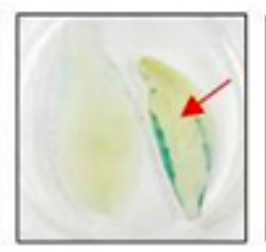

Line 3

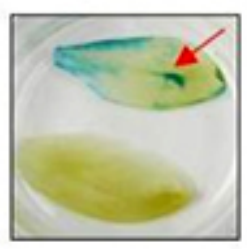

Figure 4. Enhanced expression of genome integrated LSLGUS gene by transient Rep expression in transgenic pBY031 Arabidopsis. Leaves were infiltrated with pBY003 by Agrobacterium-mediated DNA delivery (red arrows). The other leaf of each pair was an untreated transgenic leaf and was included as a control. Histochemical analysis was performed after 3 DAI.

Total genomic DNA was prepared, and $25 \mu \mathrm{g}$ of DNA was double digested with BamHI and PstI for Southern blot analysis. Hybridization temperature was $45^{\circ} \mathrm{C}$ for DNA and $50^{\circ} \mathrm{C}$ for RNA, respectively.

\section{RESULTS}

\section{GFP expression in Arabidopsis thaliana leaves}

Figure 1 illustrates the vector constructs used in the experiments described in this paper. pBY003 contains the entire genome of the wild type virus. pBY030 and pBY031 contain the GUS and GFP ORFs, under control of the $35 \mathrm{~S}$ promoter, and within the LIR-SIR-LIR (LSL) cassette. pBY003, pBY030, and pBY031 are within the binary vector pGPTV-Kan for Agrobacterium-mediated infiltration. The vector pGPTV-Kan enables the left and right borders of the binary vector, as well as reporter gene, to be integrated into the plant genome. Construction of pRep110 and p $\delta$ REP110, expressing unspliced and spliced versions of the Rep gene under $35 \mathrm{~S}$ promoter control, were described previously by Mor et al. (2003).

To examine the ability of Rep to support replication and gene expression of the LSL virus expression cassette, construct pBY030 was infiltrated into Arabidopsis leaves in the presence or absence of pBY003, containing the entire BeYDV genome (Figure 2). When Rep was provided from a separate cassette, the LSL construct containing the GFP reporter genes was released and replicated extrachromosomally. At one DAI, GFP expression was greatly enhanced in comparison to control leaf samples which were infiltrated with the expression cassette alone (Figure 2). GFP expression appeared to fade at days 3 and 5 DAI (5 DAI data not shown). To avoid the possibility that gene silencing may play a role in this decrease in reporter 


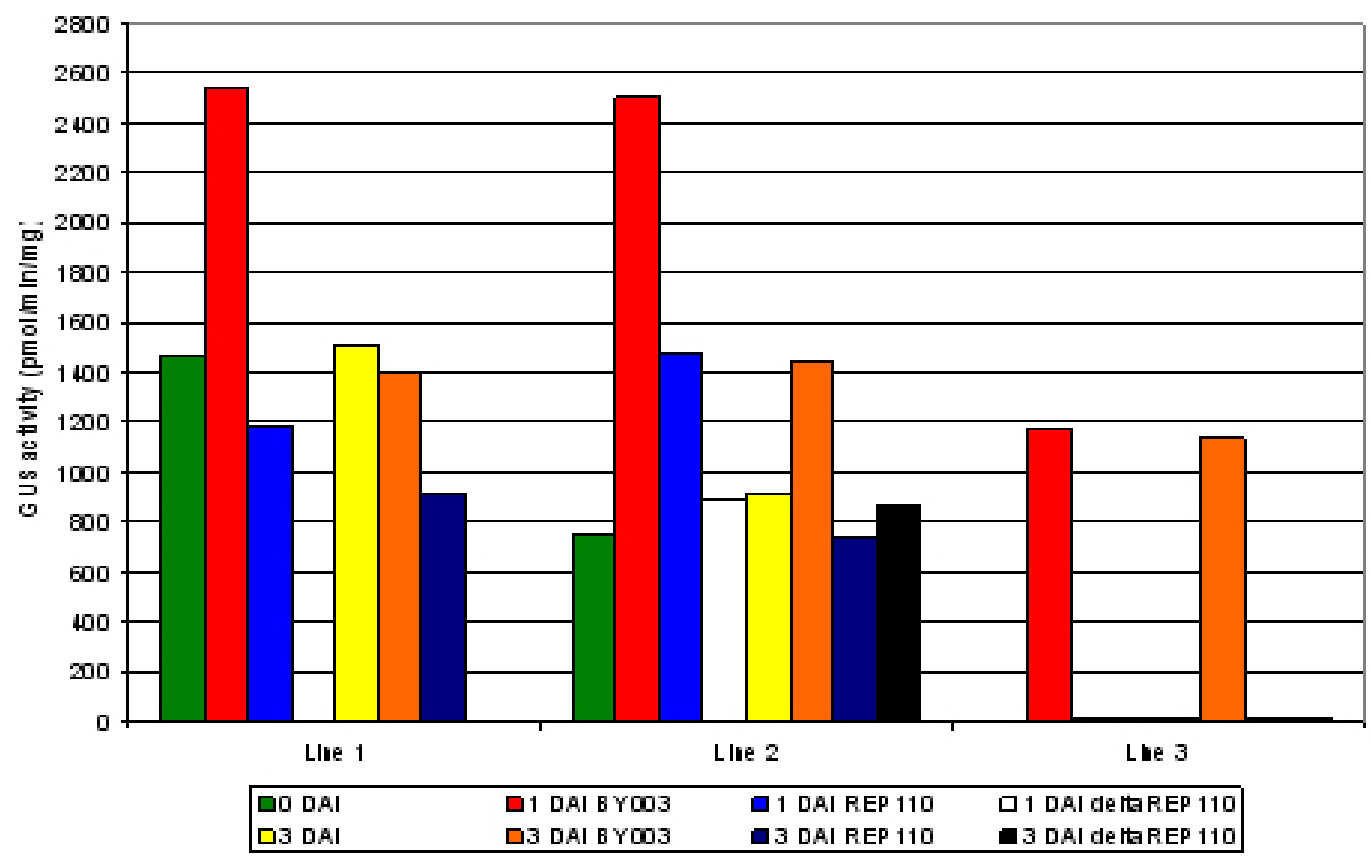

Figure 5. GUS enzymatic assay of genome integrated LSL-GUS gene by Rep protein in trans. pBY003, pREP110, or pסREP110 was infiltrated into transgenic Arabidopsis. Total protein was subjected to GUS enzymatic assay 0, 1, and 3 DAI. Lines are numbered as in Figure 4.

gene expression over a prolonged period of time, leaf samples were used at one or three DAI in further experiments.

\section{Amplification of a genome-integrated BeYDV replicon expressing a GUS reporter gene}

Previously, a BeYDV replicon carried on a plasmid was shown to be amplified by transient expression of Rep in cobombarded NT-1 cells (Hefferon and Dugdale, 2003; Mor et al. 2003). In the current study, transgenic Arabidopsis plants carrying genome-integrated copies of pBY031 (LSL-GUS) were used for transient expression studies in which construct pBY003 containing Rep expressed from the wild type virus were delivered into the leaves of transgenic Arabidopsis using Agrobacteriummediated infiltration. Upon Rep delivery, leaf samples were examined for several days after infiltration. Results from GUS histochemical staining revealed enhanced GUS expression in two separate transgenic Arabidopsis lines at 3 DAI (Figure 3). The pattern of GUS expression and the level of enhancement varied from modest to extreme among all transgenic lines (Figure 3, data not shown).

\section{Expression of GUS expression cassettes in Arabidopsis}

To determine the efficiency at which Rep could support GUS expression from reporter plasmid pBY031, Rep constructs were Agrobacterium-infiltrated into both a transformed and a transient assay system using Arabidopsis leaves. Transgenic pBY031 Lines 1, 2, and 3 were randomly selected and examined for GUS expression levels and compared to results taken from non transformed plants co-infiltrated with expression cassette pBY031 with or without various constructs expressing Rep (Figure 4). For the non transformed system, pBY031 was mixed with Agrobacterium harboring pBY003, pREP110 or p $\delta$ REP 110 constructs expressing the Rep gene product. The mixed cultures were then co-infiltrated into non transformed Arabidopsis leaves. Samples were collected at 1 and 3 DAI. The levels of GUS activity were determined, and the results are depicted in Figure 3. From these results, it appears that GUS activity was greatest when pBY031 (containing the GUS reporter cassette) was co-infiltrated along with pBY003 (containing the wild type virus). Levels of GUS activity were also high when pREP110 was used as the Rep expressing construct. However, levels of GUS activity were markedly lower when pəREP110 was used, more resembling GUS expression levels of the reporter construct pBY031 alone in the absence of any Rep construct. At 3 DAI, levels of GUS expression dropped significantly for all samples.

The results of the transient assay were compared to a similar series of experiments performed with transgenic plant lines which contained an integrated copy of the GUS expression cassette pBY031 and were infiltrated with various constructs expressing Rep (Figure 5). Leaf samples were harvested at 0, 1, and 3 DAI with Agrobacterium carrying Rep cassettes pBY003, pREP110, or p RREP110. 
In all three lines, the greatest levels of GUS activity were found when transgenic lines were infiltrated with construct pBY003, containing the wild type virus. Expression levels decreased when Rep expression was derived from pREP110, and were the lowest when the intronless form of Rep was expressed from construct p $\delta$ REP110. GUS expression levels for all constructs decreased at 3 DAI.

A considerable amount of variability was also exhibited between the three transgenic lines analyzed. While lines 1 and 2 produced similar levels of GUS expression when constructs pBY003 and pREP110 were included, only line 2 exhibited visible levels of GUS activity when p $\delta E P 110$ was infiltrated in transgenic Arabidopsis. Furthermore, only modest levels of GUS activity were observed for line 3 infiltrated with pBY003 (wild type virus). No discernable level of GUS activity was seen when transgenic line 3 was infiltrated with either pREP110 or p $\delta$ REP110.

It is possible that the changes in GUS expression in these transgenic lines may be the result of gene silencing. To verify the relationship between DNA replication and RNA transcription of the genome-integrated GUS gene by transient Rep expression, both Northern and Southern blot analyses were performed (Figure 6 and Figure 7). For Northern blot analysis, GUS transcript signals were normalized to a small ribosomal RNA signal using the ImageQuantTM software program. In transgenic line 1, GUS mRNA transcript levels decreased for plants infiltrated with both pBY003 (wild type virus) and
pREP110 at 3 DAI, however, samples infiltrated with p $\delta$ REP110 (intronless Rep) exhibited a greatly reduced transcript level both at 1 and 3 DAI. In transgenic line 2, GUS mRNA transcript levels were slightly enhanced at 1 DAI when Rep was expressed via construct pBY003. Transcript levels decreased significantly for samples taken from transgenic line 2 infiltrated with pREP110 and p $\delta$ REP 110 at 3 DAI. Transgenic line 3 also exhibited decreases in GUS activity in all samples at 3 DAI (Figure $6)$.

To examine relative replication efficiencies of the released reporter construct in these transgenic lines, total genomic DNA was prepared and double-digested with BamHI and PstI, and Southern blot analysis was performed using DIGlabeled GUS (Figure 7a) and Rep specific probes (Figure $7 b)$. The restriction maps in Figure $7 \mathrm{c}$ depict the possible sizes of DNA fragments which could hybridize with the GUS and Rep cDNA probes. Little DNA could be detected from samples which had not been infiltrated with constructs containing the Rep ORFs (Figure 7a and Figure 7b, lanes 1 and 5); the small amount of DNA visible is derived from the pBY028 construct integrated into the plant genome. A much greater amount of signal was apparent in Figure $7 \mathrm{a}$ lanes 2; this increase in signal is the result of the excised plasmid replicating extrachromasomally. The results indicate that all replication products for samples infiltrated with constructs pBY031 and pREP110 could be detected at their predicted sizes at both 1 and $3 \mathrm{DAI}$; the relative levels of replication products for samples infiltrated with
Line 1

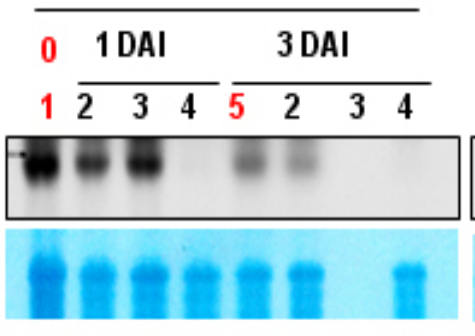

\section{Normalization: RNA transcrit signal / rRNA signal by ImageQuant ${ }^{\top \mathrm{M}}$ software}

\begin{tabular}{|c|c|c|c|c|c|c|c|c|}
\hline & 1 & 2 & 3 & 4 & 5 & 2 & 3 & 4 \\
\hline ne & $\begin{array}{l}1.10 \\
0.12\end{array}$ & & & $\begin{array}{l}0.16, \\
0.21,\end{array}$ & $\begin{array}{l}0.92, \\
0.27,\end{array}$ & $\begin{array}{l}0.69, \\
0.75 \text {, }\end{array}$ & $\begin{array}{l}1.19, \\
0.25,\end{array}$ & $\begin{array}{l}0.10 \\
0.05\end{array}$ \\
\hline & 0.08 & 0.26 & 0.53 , & 0.90 & 0.16 & 0.06 & 0.18 & 0.18 \\
\hline
\end{tabular}

1. 0 DAI (-)

2. BY003

3. REP110

4. రREP110

5. 3 D Al (-)

Figure 6. Transcription of rescued genome integrated LSL-GUS gene in transgenic pBY031 Arabidopsis. Plant lines and treatments are the same as those in Figure 5. One of pBY003 (entire virus genome), pREP110 (unspliced Rep ORF), or pסREP110 (spliced Rep ORF) was included to supply Rep. The red color at 0 and 3 DAl indicates no treatment. Total RNA was purified and used for Northern blot analysis. DIG-labeled GUS specific probe was used (upper panel). The transcript signal of GUS was normalized by a small ribosomal RNA signal from the methylene blue-stained blot (lower panel) using ImageQuant ${ }^{\mathrm{TM}}$ software program. The table at bottom shows the normalized data for each treatment. 
p $\delta$ REP110, however, were generally lower for each transgenic plant line. In the case of line 3 , the only significant replication products that could be observed were when plant tissue was infiltrated with construct pBY003, containing the wild type genome.

\section{DISCUSSION}

In plants, one of the most well-established mechanisms involved in the cellular defence against viruses is RNA silencing. Several distinct but partially overlapping pathways that are commonly triggered by double-stranded RNA (dsRNA) have now been elucidated. Many of these pathways, for example, post-transcriptional gene silencing (PTGS), which results in the degradation of target mRNA, involve a number of factors including the ribonuclease Dicer and RNA-dependent RNA polymerase (RDR) (Matzke and Matzke, 1995). The precise virus-host interactions which are involved in RNA silencing are rather complex; the outcome of a virus infection most likely depends upon a balance between the recognition of features of particular virus by the plant host and the efficiency of virus silencing suppressors which reside within a specific plant host.

Geminiviruses possess both the properties required for amplification of foreign genes as well as an effective means by which to induce gene silencing. In the latter case, silencing could be the result of dsRNA produced from overlapping ORFs of the geminivirus genome (Bisaro, 2006). Geminivirus susceptibility to RNA silencing has been confirmed by experiments demonstrating that synthetic small interfering RNA (siRNA) which were designed to target the coding region of the Rep protein of African cassava mosaic virus (ACMV) interfered with the accumulation of Rep mRNA (Vanitharani et al. 2004). Geminivirus transcripts can be subjected to RNA silencing as a consequence of transcript overlap, which contributes to the production of dsRNA. In addition, host RDR activity is thought to possibly function on over-expressed viral mRNAs. On the other hand, Atkinson et al. (1998) reported that PTGS in petunia using a TYDV vector was due to enhanced episome copy number. When the ChsA, driven by the $35 \mathrm{~S}$ CaMV promoter, was cloned into a TYDV-based vector, random white-spotted flowers were produced in petunia as a result of an increase in episomal copy number. The spots were found at random locations in the flower petals and occurred at high frequency. Further examination revealed a down-regulation of ChsA transcript level, suggesting that gene silencing of both episomal and endogenous ChsA was taking place. The degree of silencing correlated to the episomal copy number in the plant genome (Atkinson et al. 1998).

Viruses from various families have acquired several unrelated suppressors of gene silencing that affect different and perhaps multiple steps in the silencing pathway, resulting in an enhancement of disease and a promotion of viral invasiveness. HC-Pro of potyviruses, p19 of tombusviruses, the CP of turnip crinkle virus (TCV), the $2 b$ protein of cucumber mosaic virus (CMV) and p25 of potexviruses have all been implicated in suppressing various stages of the gene silencing network of pathways. A number of proteins which play a role in suppressing gene silencing have also been identified in geminiviruses. For example, the AL2 or TrAP protein of begomoviruses, a
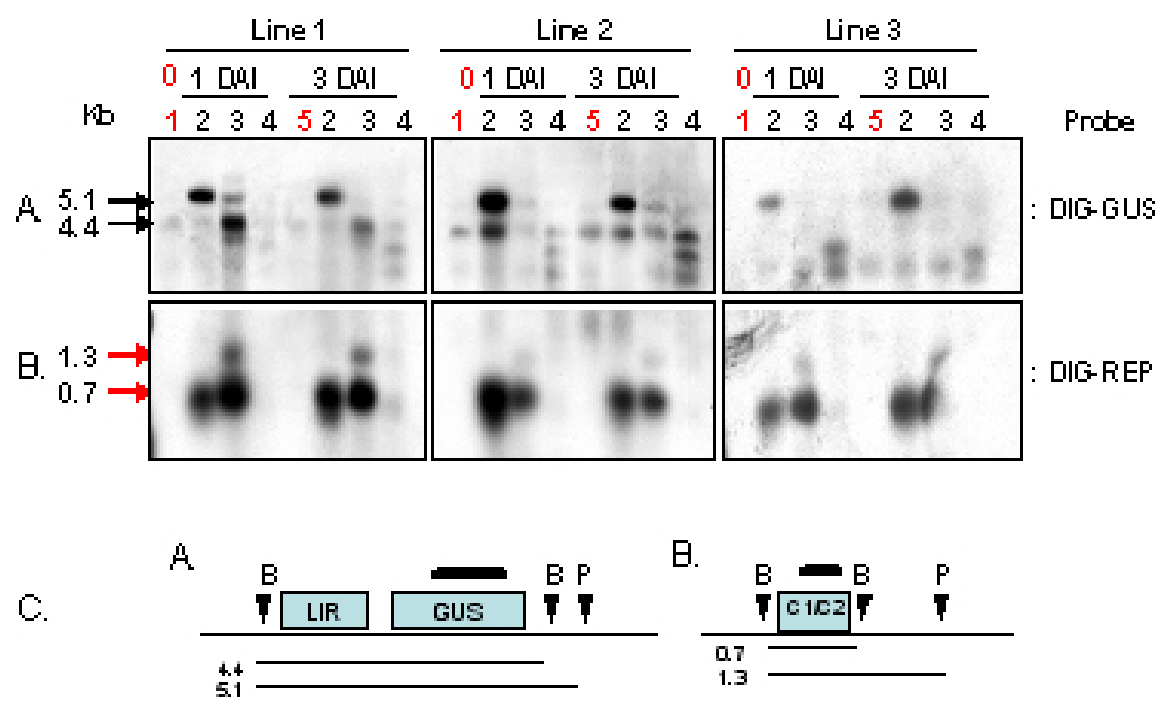

Figure 7. Rescued genome integrated LSL-GUS gene replication by transient Rep expression using Agrobacterium-mediated DNA delivery. Plant lines and treatments are described in Figure 5. Total genomic DNA was isolated, double digested with BamHI and Pstl, and hybridized with GUS and Rep specific DIG-labeled cDNA probes. C. Restriction maps depict regions surrounding areas corresponding to either GUS or Rep probes. B; BamHI, P; Pstl, Bar; span of cDNA probe. Lengths of restriction fragments indicated in $\mathrm{kbp}$ on left hand side of Figure. 
family belonging to the geminiviridae, is a transcription factor found to be required for the expression of late viral genes, and has been shown to be capable of reversing established gene silencing (Voinnet et al. 1999). More detailed studies have revealed that AC2 can suppress silencing in a more indirect manner, by activating the expression of a cellular protein that possibly functions as an endogenous negative regulator of the system (Trinks et al. 2005). In addition, the AC4 gene, which lies in a different open reading frame within the Rep coding region of begomoviruses, also has been shown to possess silencing activity (Vanitharani et al. 2004). To date, no suppressors of gene silencing have yet been identified for the mastreviridae (Bisaro, 2006).

In the expression system described in this paper, Arabidopsis leaves harboring the LSL-GFP reporter cassette were infiltrated by Agrobacteria transformed with constructs containing the Rep gene. The results of this study would suggest that the phenomenon of gene silencing could indeed have a negative contribution to the expression system over time. Quantification of GUS activity collected from both transient assays and transgenic plants infiltrated with constructs supplying Rep indicated that a significant decrease in gene expression took place over a period of several days, further implying that gene silencing plays a significant role in determining the parameters at which foreign gene expression is optimal. Northern blot analysis confirmed that the loss in GUS activity over time corresponded with a decline in mRNA transcript levels.

When the construct containing the spliced form of Rep ( $\delta$ Rep; removed intron) was used both in transient assay and in transgenic plant expression experiments, a marked decrease in GUS activity was observed. These results were supported by Southern blot data which demonstrated that plant samples containing dintron replicated at a lower efficiency than those containing unspliced versions of Rep. These data suggest that RepA plays an important role not only in the BeYDV expression system, but in virus replication in general. While these results are contrary to previous studies by Hefferon and Dugdale (2003), the experiments presented here involve Agrobacteriuminfiltration as the delivery system, whereas the results of the latter were performed by biolistic delivery. Differences in results may therefore be due to the differences in the delivery system utilized.

Of the three transgenic lines studied in this paper, lines 1,2 and 3 proved to express the greatest level of GUS activity when Rep was supplemented through another construct by Agrobacterium-mediated infiltration. Coinfiltration with the wild type virus construct (pBY003) provided the greatest levels of reporter gene expression in all three lines. The results of the Northern blot analysis support the GUS assay data with respect to relative abundance of mRNA transcript. The best results were found for the transient assay data, in which again, plants infiltrated with both the expression cassette and wild-type virus exhibited the best results, followed by plants infiltrated with the unspliced and spliced versions of Rep, respectively. The reasons for the differences in expression between transgenic lines and transient assays are not entirely clear. However, the use of a transgenic line requires the additional step of excising a nascent BeYDV-based replication product from the plant host genome. Perhaps this extra step renders the expression system less efficient. It is also possible that additional factors such as the chromosomal state of the host genome may lower the likelihood of Rep supplied in trans from initiating replication from a pro-virus in an integrated state.

These results represent a crucial step in the development and future utilization of a deconstructed expression system strategy using Rep supplied in trans and separated from the rest of the expression vector by independent promoter control. We have shown here that while Rep could indeed effectively activate replication of the expression vector and subsequently increase expression of a reporter gene, gene silencing can have a major inhibitory effect on the system as a whole. Decreases in RNA transcript level were detected as early as 3 days post-infiltration, and could lower the efficiency of the system significantly. We conclude that measures must be taken to avoid silencing effects and to increase system productivity. These factors can be achieved by: (1) taking advantage of the assortment and accessibility of plant virus suppressors of gene silencing which have been identified so far, and incorporate one or more into our expression system so as to prevent the deleterious effects of silencing from taking place. This could easily be achieved by coinfiltrating a suppressor of gene silencing along with the Rep cassette, or by using transgenic plants which already express a suppressor of silencing as a starting point for future expression studies. (2) Another means by which to increase system efficiency is to maintain Rep under tighter promoter control, so that induction of the expression cassette can be manipulated in such a way as to evade silencing. This would involve the careful selection of inducible or developmental promoters for Rep expression. (3) The efficiency of the system can again be increased by utilizing novel methods to deliver the expression vector and Rep constructs to the plant host. Magnifection, for example, has been shown to increase transfection efficiency enormously and does not require systemic movement of the virus to achieve optimal results. This procedure takes place by the immersion of an entire plant into a suspension of Agrobacterium and application of a weak vacuum, followed by a gentle return to atmospheric pressure (Gleba et al. 2005; Marillonnet et al. 2005). This results in an infiltration of the Agrobacterium suspension containing the construct(s) of interest into the intercellular space of all mature leaves of the plant host. The end result of using this procedure is that a larger proportion of plant cells become 
infiltrated with the construct(s) in a more synchronous manner, and reporter gene expression is enhanced tremendously. Application of one or all of these measures should be incorporated into the design of future BeYDV expression systems for optimal yield of foreign protein.

In conclusion, the results of this study point out the promise as well as the obstacles that must be overcome for the use of the BeYDV expression system for the production of vaccine proteins at high levels in plant tissue.

\section{ACKNOWLEDGMENTS}

The authors would like to thank Dr. Jeong Mee Park for assistance with GUS histochemical stain experiments, as well as Drs. Kenneth E. Palmer and John Stanley for providing the BeYDV virus and intronless Rep constructs, respectively.

\section{REFERENCES}

ALLEN, George C.; HALL, Gerald E.; CHILDS, Lisa C.; WEISSINGER, Arthur K.; SPILER, Steven and THOMPSON, William F. Scaffold attachment regions increases reporter gene expression in stably transformed plant cells. The Plant Cell, June 1993, vol. 5, no. 6, p. 603613.

ATKINSON, Ross G.; BIELESKI, Lara R.F.; GLEAVE, Andrew P.; JANSSEN, Bart-Jan and MORRIS, Bret A.M. Post-transcriptional silencing of chalcone synthase in petunia using a geminivirus-based episomal vector. The Plant Journal, September 1998, vol. 15, no. 5, p. 593-604.

BECKER, Detlef; KEMPER, Elke; SCHELL, Jeff and MASTERSON, Robert. New plant binary vectors with selectable markers located proximal to the left T-DNA border. Plant Molecular Biology, December 1992, vol. 20, no. 6, p. 1195-1197.

BISARO, David M. Silencing suppression by geminivirus proteins. Virology, January 2006, vol. 344, no. 1, p. 158168.

BRADFORD, Marion M. A rapid and sensitive methods for the quantitation of microgram quantities of protein utilizing the principle of protein-dye binding. Analytical Biochemistry, May 1976, vol. 72, no. 1-2, p. 248-254.

CLOUGH, Steven J. and BENT, Andrew F. Floral Dip: A Simplified Method for Agrobacterium-Mediated Transformation of Arabidopsis thaliana. The Plant Journal, December 1998, vol. 16, no. 6, p. 735-743.

DONSON, J.; MORRIS-KRSINICH, B.A.M.; MULLINEAUX, P.M.; BOULTON, M.I. and DAVIES,
J.W. A putative primer for second-strand DNA synthesis of maize streak virus is virion-associated. The EMBO Journal, December 1984, vol. 3, no. 13, p. 3069-3073.

GLEBA, Yuri; MARILLONNET, Sylvestre and KLIMYUK, Victor. Engineering viral expression vectors for plants: the 'full virus' and the 'deconstructed virus' strategies. Current Opinions in Plant Biology, April 2004, vol. 7, no. 2, p. 182-188.

GLEBA, Yuri; KLIMYUK, Victor and MARILLONNET, Sylvestre. Magnifection-a new platform for expressing recombinant vaccines in plants. Vaccine, March 2005, vol. 23, no. 17-18, p. 2042-2048.

HANLEY-BOWDOIN, Linda; ELMER, J. Scott and ROGERS, Stephen G. Expression of functional replication protein from tomato golden mosaic virus in transgenic tobacco plants. Proceedings of the National Academy of Sciences of the United States of America, February 1990, vol. 87 , no. 4 , p. 1446-1450.

HAYES, R.J.; PETTY, I.T.D.; COUTTS, R.H.A. and BUCK. K.W. Gene amplification and expression in plants by a replicating geminivirus vector. Nature, July 1988, vol. 334 , no. 6178 , p. $179-182$.

HEFFERON, Kathleen L. and DUGDALE, Ben. Independent expression of Rep and RepA and their roles in regulating bean yellow dwarf virus replication. Journal of General Virology, December 2003, vol. 84, no. 12, p. 34653472 .

HEFFERON, Kathleen L. Novel approaches to protein expression using plant virus expression vectors. Global Science Books, 2006, vol. 11, p. 30-40.

HEFFERON, Kathleen L. Transgenic Plants and Biotechnology. In: Encyclopedia of Life Sciences Support Systems. 2007. UNESCO, Eolss Publishers, Oxford, UK. 2007. Abailable from internet: http://www.eolss.net.

JEFFERSON, R.A.; KAVANAGH, T.A. and BEVAN, M.W. Gus fusions: beta-glucuronidase as a sensitive and versatile gene fusion maker in higher plants. The EMBO Journal, December 1987, vol. 6, no. 13, p. 3901-3907.

KAMMANN, Matthias; MATZEIT, Volker; SCHMIDT, Bodo; SCHELL, Jeff; WALDEN, Richard and GRONENBORN, Bruno. Geminivirus-based shuttle vectors capable of replication in Escherichia coli and monocotyledenous plant cells. Gene, August 1991, vol. 104, no. 2, p. 247-252.

KJEMTRUP, Susanne; SAMPSON, Kim S.; PEELE, Charles G.; NGUYEN, Long V.; CONKLING, Mark A.; 
THOMPSON, William F. and ROBERTSON, Dominique. Gene silencing from plant DNA carried by a geminivirus. The Plant Journal, April 1998, vol. 14, no. 1, p. 91-100.

KUMAGAI, M.H.; DONSON, J.; DELLA-CIOPPA, G.; HARVEY, D.; HANLEY, K. and GRILL, L.K. Cytoplasmic Inhibition of Carotenoid Biosynthesis with Virus-Derived RNA. Proceedings of the National Academy of Sciences of the United States of America, February 1995, vol. 92 , no. 5 , p. 1679-1683.

LINDBO, John A.; FITZMAURICE, Wayne P. and DELLA-CIOPPA, Guy. Virus-mediated reprogramming of gene expression in plants. Current Opinion in Plant Biology, June 2001, vol. 4, no. 3, p. 181-185.

LIU, Li; DAVIES, Jeffrey W. and STANLEY, John. Mutational analysis of bean yellow dwarf virus, a geminivirus of the genus Mastrevirus that is adapted to dicotyledonous plants. Journal of General Virology, September 1998, vol. 79, no. 9, p. 2265-2274.

MA, Julian K.; CHIKWAMBA, Rachel; SPARROW, Penny; FISCHER, Rainer; MAHONEY, Richard and TWYMAN, Richard M. Plant-derived pharmaceuticals-the road forward. Trends in Plant Science, December 2005, vol. 10 , no. 12 , p. $580-585$.

MARILLONNET, Sylvestre; THOERINGER, Carola; KANDZIA, Romy; KLIMYUK, Victor and GLEBA, Yuri. Systemic Agrobacterium tumefaciens-mediated transfection of viral replicons for efficient transient expression in plants. Nature Biotechnology, June 2005, vol. 23, no. 6, p. 718723.

MATZKE, Marjori A. and MATZKE, Antonius J.M. How and why do plants inactivate homologous (trans)genes? Plant Physiology, March 1995, vol. 107, no. 3, p. 679-685.

MOON, Y.-S. and HEFFERON, Kathleen L. Geminivirus replication. In: Recent Advances in DNA Virus Replication. Transworld Sciences International, 2007, p. 329-334.

MOR, Tsafrir S.; MOON, Yong-Sun; PALMER, Kenneth E. and MASON, Hugh S. Geminivirus vectors for highlevel expression of foreign proteins in plant cells. Biotechnology and Bioengineering, February 2003, vol. 81, no. 4 , p. $430-437$.

MORRIS, Bret A.; RICHARDSON, Kim A.; HALEY, Ann; ZHAN, Xiangcan and THOMAS, John E. The nucleotide sequence of the infectious cloned DNA component of tobacco yellow dwarf virus reveals features of geminiviruses infecting monocotyledonous plants. Virology, April 1992, vol. 187, no. 2, p. 633-642.
RATCLIFF, Frank; MARTIN-HERNANDEZ, Ana Montserrat and BAULCOMBE, David C. Tobacco rattle virus as a vector for analysis of gene function by silencing. The Plant Journal, January 2001, vol. 25, no. 2, p. 237-245.

RODRIGUES-POUSADA, Renato Alberto; RYCKE, Riet De; DEDONDER, Andrée; CAENEGHEM, Wim Van; ENGLER, Gilbert; MONTAGU, Marc Van and STRAETEN, Dominique Van Der. The Arabidopsis 1Aminocyclopropane-1-Carboxylate Synthase Gene 1 Is Expressed During Early Development. The Plant Cell, August 1993, vol. 5, no. 8, p. 897-911.

RUIZ, M. Teresa; VOINNET, Olivier and BAULCOMBE, David C. Initiation and maintenance of virus-induced gene silencing. The Plant Cell, June 1998, vol. 10, no. 6, p. 937946.

SAMBROOK, Joseph; FRITSCH, Edward F. and MANIATIS, Tom. Molecular cloning: a laboratory manual, 2nd ed. NY, Cold Sprin 0879693732 g Harbor Laboratory Press, 1989. 638 p. ISBN 0879693732.

STREATFIELD, Stephen J. and HOWARD, John A. Plant production systems for vaccines. Expert Review of Vaccines, December 2003, vol. 2, no. 6, p. 763-775.

TANG, Xiaoyan; FREDERICK, Reid D.; ZHOU, Jianmin; HALTERMAN, Dennis A.; JIA, Yulin and MARTIN, Gregory B. Initiation of plant disease resistance by physical interaction of AvrPto and Pto kinase. Science, December 1996, vol. 274, no. 5295, p. 2060-2063.

TIMMERMANS, Marja C.P.; DAS, O. Prem and MESSING, Joachim. Trans replication and high copy numbers of wheat dwarf virus vectors in maize cells. Nucleic Acids Research, August 1992, vol. 20, no. 15, p. 4047-4054.

TRINKS, D.; RAJESWARAN, R.; SHIVAPRASAD, P.V.; AKBERGENOV, R.; OAKELEY, E.J.; VELUTHAMBI, K.; HOHN, T. and POOGGIN, M.M. Suppression of RNA silencing by a geminivirus nuclear protein, $\mathrm{AC} 2$, correlates with transactivation of host genes. Journal of Virology, February 2005, vol. 79, no. 4, p. 2517-2527.

VANITHARANI, Ramachandran; CHELLAPPAN, Padmanabhan; PITA, Justin S. and FAUQUET, Claude M. Differential roles of Ac2 and AC4 of cassava geminiviruses in mediating synergism and suppression of posttranscriptional gene silencing. Journal of Virology, September 2004, vol. 78, no. 17, p. 9487-9498.

WALMSLEY, Amanda M. and ARNTZEN, Charles J. Plants for delivery of edible vaccines. Current Opinion in Biotechnology, April 2000, vol. 11, no. 2, p. 126-129. 